\title{
The impact of life tables adjusted for smoking on the socio-economic difference in net survival for laryngeal and lung cancer
}

\author{
L Ellis ${ }^{\star 1}$, M P Coleman ${ }^{1}$ and B Rachet ${ }^{1}$ \\ ${ }^{1}$ Cancer Research UK Cancer Survival Group, London School of Hygiene and Tropical Medicine, Keppel Street, London WC1E \\ 7HT, UK
}

Background: Net survival is a key measure in cancer control, but estimates for cancers that are strongly associated with smoking may be biased. General population life tables represent background mortality in net survival, but may not adequately reflect the higher mortality experienced by smokers.

Methods: Life tables adjusted for smoking were developed, and their impact on net survival and inequalities in net survival for laryngeal and lung cancers was examined.

Results: The 5-year net survival estimated with smoking-adjusted life tables was consistently higher than the survival estimated with unadjusted life tables: $7 \%$ higher for laryngeal cancer and 1.5\% higher for lung cancer. The impact of using smoking-adjusted life tables was more pronounced in affluent patients; the deprivation gap in 5-year net survival for laryngeal cancer widened by $3 \%$, from $11 \%$ to $14 \%$.

Conclusions: Using smoking-adjusted life tables to estimate net survival has only a small impact on the deprivation gap in survival, even when inequalities are substantial. Adjusting for the higher, smoking-related background mortality did increase the estimates of net survival for all deprivation groups, and may be more important when measuring the public health impact of differences or changes in survival, such as avoidable deaths or crude probabilities of death.

Net survival is a key measure of interest for cancer control. It is defined as the survival of cancer patients in the hypothetical situation, where they cannot die from causes other than cancer. Net survival 'corrects' the all-cause survival of a group of cancer patients by taking into account mortality due to other causes (the so-called expected or background mortality), that is, the mortality the patients would experience if they did not have cancer. When the cause of death is not reliably known for all patients, such as in population-based cancer registry data, the expected mortality of the patients is provided by life tables of the general population with the same socio-demographic characteristics as the cancer patients. This expected mortality is subtracted from the all-cause mortality for a group of cancer patients, thus enabling interpretation to focus on mortality in excess of the background mortality, which is then considered attributable to the cancer. Because background mortality is higher among smokers, the use of general life tables, unadjusted for smoking, may produce biased estimates of survival for cancers that are strongly associated with smoking. Such unadjusted life tables will provide under-estimated expected mortality, leading to overestimation of the excess (cancer-related) mortality of patients who are smokers (Figure 1). Consequently, net survival estimated on the basis of these unadjusted life tables may be an underestimate of the 'true' net survival.

This theory was first proposed in 1961 by Ederer, who constructed approximate life tables for smokers, derived from mortality data from a cohort study, and tested their impact on survival estimates. The life tables for smokers made very little difference to the survival estimates, although this analysis was for 


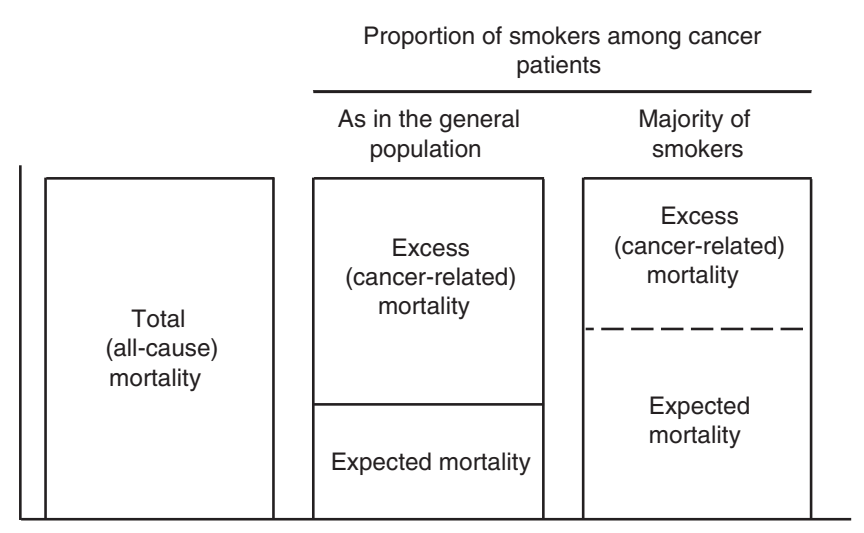

Figure 1. Partition of the total (all-cause) mortality of a group of cancer patients into background (expected) mortality and excess (cancerrelated) mortality among the general population and among smokers.

all cancers combined: a smaller impact would therefore be expected (Ederer et al, 1961). Ederer's life tables might have made more difference to the estimates of survival for cancers that are strongly associated with smoking, such as cancer of the larynx and lung. Two recent studies investigated this issue using different methods in different contexts, and, although they did not generally observe a strong impact of the use of life tables for smokers on relative survival estimates, the conclusions may differ according to the type of cancer (Blakeley et al, 2012; Hinchliffe et al, 2012).

While life tables adjusted for smoking may produce less-biased estimates of survival overall, they may also affect the known socioeconomic gradient in net survival for some cancers, depending on whether national or deprivation-specific life tables are used. The prevalence of smoking in the general population differs between socio-economic groups: in 2008, the prevalence of smoking in deprived groups (routine and manual socio-economic category) was $29 \%$, compared to $14 \%$ in the most affluent (managerial and professional socio-economic category) (Office for National Statistics, 2010). The prevalence of smoking in the general population must be compared to that observed in patients diagnosed with laryngeal or lung cancer, the majority of whom are assumed to be smokers. The differential in smoking prevalence between the general population and cancer patients will therefore be larger in the more affluent groups than in the more deprived. The use of smoking-adjusted life tables will increase the estimates of net survival for all deprivation groups, but more so for the most affluent patients. This would result in a steeper deprivation gradient in net survival between affluent and deprived patients. This paper describes the methodology used in the development of life tables adjusted for smoking, and the extent of their impact on net survival estimates and inequalities in survival for laryngeal and lung cancers.

\section{MATERIALS AND METHODS}

A life table is simply a set of age- and sex-specific mortality rates for a specified population, and is constructed from the number of deaths and the population counts. In order to produce a life table that is specific for smokers directly from the raw data, both the number of deaths and the populations would need to be available by smoking status. These data are not available nationally in the UK. An alternative method was developed, which involved adjusting existing national and deprivation-specific life tables (Cancer Research UK Cancer Survival Group, 2009) with published ageand sex-specific estimates of smoking-related mortality. It was not possible, or indeed necessary, to make any adjustment in the younger age groups, as both the prevalence of smoking and the hazard rate ratio of death associated with it are low.

Many studies have been published on the effect of smoking on allcause mortality in a variety of populations and age groups (Carstensen et al, 1987; Floderus et al, 1988; LaCroix et al, 1991; Tverdal et al, 1993; Doll et al, 1994; Illing and Kaiserman, 1995; Thun et al, 1995; Prescott et al, 1998; Jacobs et al, 1999; Qiao et al, 2000; Nilsson et al, 2001; Ezzati and Lopez, 2003; Doll et al, 2004; Rodu and Cole, 2004; Blakely and Wilson, 2005; Zorrilla-Torras et al, 2005; Jha et al, 2006; Vollset et al, 2006; Kenfield et al, 2008; Woloshin et al, 2008; Gruer et al, 2009). The direction of the relative measures reported was consistent, although the magnitude of the hazard rate ratios differed, depending on whether the studies examined light, moderate or heavy smokers, or all smokers combined. Only a few studies have directly estimated the effect of smoking on all-cause mortality in people from different deprivation groups. Therefore, a number of assumptions need to be made when adjusting life tables for smoking: (1) about the effect of deprivation on mortality in smokers, and (2) about the magnitude of the hazard ratio.

Background mortality in the general population is known to differ by deprivation, and deprivation-specific life tables are required to produce less biased estimates of the deprivation gap in net survival. In the first scenario (S1), we consider that the higher mortality among smokers differs by deprivation group, to the same degree as in the general population. Under S1, a deprivation-specific life table was produced, taking into account the different prevalence of smoking in each deprivation group. In contrast, the second scenario (S2) assumes that in smokers this socio-economic gradient in background mortality does not exist. Under S2, a national life table was produced, adjusted for the higher background mortality (and hence lower expected survival) among smokers, but with no deprivation gradient. Within each scenario outlined above, a range of adjustments was explored, based on the lowest, average and highest hazard ratios reported in the literature (Table 1). The adjustments are termed as A1 (lowest level of adjustment), A2 (average) and A3 (highest).

The hazard rate ratios obtained from the literature were largely from cohort studies, and hence were for smokers compared to non-smokers, rather than smokers compared to the general population. The following formulae were applied to derive the all-cause mortality rates in smokers and non-smokers, taking into account the prevalence of smoking for each sex, age and (where appropriate) deprivation group:

For each sex and age group:

$$
\begin{aligned}
& R 0=R \times 1 /(P 0+\mathrm{RR} \times P 1) \\
& R 1=R \times 1 /(P 0 / \mathrm{RR}+P 1)
\end{aligned}
$$

where $R 0$ is the all-cause mortality rate in non-smokers, $R 1$ is the all-cause mortality rate in smokers, $R$ is the all-cause mortality rate in the general population (from the unadjusted life table), $P 0$ is the proportion of non-smokers in the general population, $P 1$ is the proportion of smokers in the general population, and RR is the hazard rate ratio of all-cause mortality between smokers and non-smokers.

The adjustments were applied to the age- and sex-specific mortality rates in England in 2001, according to the assumptions described above. To smooth these rates, we employed the flexible Poisson model we use to build our national and deprivationspecific life tables: for each sex, we model the main effects of age and, for the specific life tables, the effect modification between age and deprivation, using restricted cubic spline functions.

The impact of smoking-adjusted life tables on estimates of net survival and the deprivation gap in survival was investigated, and compared to net survival estimated using non-adjusted national and deprivation-specific life tables. The adjusted life tables represent the age-, sex- and deprivation-specific background mortality of smokers 


\begin{tabular}{|c|c|c|c|c|c|c|}
\hline \multicolumn{4}{|c|}{ Hazard rate ratio (RR) } & \multirow[b]{2}{*}{$\begin{array}{l}\text { Prevalence of } \\
\text { smoking (P1) }\end{array}$} & \multirow[b]{2}{*}{$\begin{array}{c}\text { Prevalence of } \\
\text { smoking (affluent) }\end{array}$} & \multirow[b]{2}{*}{$\begin{array}{c}\text { Prevalence of } \\
\text { smoking (deprived) }\end{array}$} \\
\hline Age & $\begin{array}{l}\text { A1 (lowest } \\
\text { adjustment) }\end{array}$ & $\begin{array}{l}\text { A2 (average } \\
\text { adjustment) }\end{array}$ & $\begin{array}{l}\text { A3 (highest } \\
\text { adjustment) }\end{array}$ & & & \\
\hline \multicolumn{7}{|l|}{ Men } \\
\hline $35-39$ & 1.8 & 2.8 & 3.9 & 0.31 & 0.22 & 0.37 \\
\hline $40-44$ & 1.8 & 2.8 & 3.9 & 0.31 & 0.22 & 0.37 \\
\hline $45-49$ & 2 & 2.8 & 3.7 & 0.31 & 0.22 & 0.37 \\
\hline $50-54$ & 2.1 & 2.9 & 3.7 & 0.26 & 0.18 & 0.31 \\
\hline 55-59 & 2.1 & 2.5 & 3.0 & 0.26 & 0.18 & 0.31 \\
\hline $60-64$ & 2.1 & 2.5 & 3.0 & 0.16 & 0.11 & 0.19 \\
\hline $65-69$ & 1.9 & 2.4 & 3.0 & 0.16 & 0.11 & 0.19 \\
\hline 70-74 & 1.8 & 2.3 & 2.8 & 0.16 & 0.11 & 0.19 \\
\hline $75+$ & 1.5 & 2.1 & 2.8 & 0.16 & 0.11 & 0.19 \\
\hline \multicolumn{7}{|c|}{ Women } \\
\hline $35-39$ & 1 & 1 & 1 & 0.31 & 0.22 & 0.37 \\
\hline $40-44$ & 1.4 & 2.1 & 2.8 & 0.28 & 0.20 & 0.34 \\
\hline $45-49$ & 1.8 & 2.3 & 2.8 & 0.28 & 0.20 & 0.34 \\
\hline $50-54$ & 1.9 & 2.3 & 2.8 & 0.25 & 0.18 & 0.30 \\
\hline $55-59$ & 2 & 2.2 & 2.5 & 0.25 & 0.18 & 0.30 \\
\hline $60-64$ & 2 & 2.2 & 2.5 & 0.17 & 0.12 & 0.20 \\
\hline $65-69$ & 1.8 & 1.9 & 2.1 & 0.17 & 0.12 & 0.20 \\
\hline $70-74$ & 1.6 & 1.8 & 2.1 & 0.17 & 0.12 & 0.20 \\
\hline $75+$ & 1.4 & 1.4 & 1.4 & 0.17 & 0.12 & 0.20 \\
\hline
\end{tabular}

in 2001. The unadjusted life tables represent the background mortality of the general population in 2001. One- and five-year net survivals were estimated for each sex and deprivation group for patients diagnosed with laryngeal or lung cancer in England during 2001-2005 and followed up to the end of 2009. The records were provided by the population-based National Cancer Registry of England, based at the Office for National Statistics. The data used for this study consisted of 86289 male and 58917 female lung cancer patients, and 7037 male and 1484 female laryngeal cancer patients. Net survival was estimated using the non-parametric estimator described by Perme et al (2012). This estimator corrects the EdererII relative survival ratio in order to account for the informative censoring associated with risk factors such as age, that is, the higher likelihood that older patients will die of other causes than their cancer (Ederer et al, 1961). The fitted deprivation gap in survival between the most affluent and most deprived groups was estimated using variance-weighted linear regression.

Since the cancer registry data do not contain any information on patients' smoking history, we were not able to categorise patients according to their smoking status. However, it has been estimated that at least $85 \%$ of laryngeal cancers and $90 \%$ of lung cancers are attributable to tobacco smoking in the UK (Anantharaman et al, 2011; Parkin, 2011). Therefore, for the purposes of these analyses, all laryngeal and lung cancer patients were assumed to have been smokers. Given the strength of the evidence for tobacco smoking as the primary risk factor for both cancers, this is a plausible assumption.

\section{RESULTS}

Net survival estimates for laryngeal and lung cancer using the smoking-adjusted life tables (either national or deprivation-specific) were consistently higher than survival estimated using the corresponding unadjusted life tables. The magnitude of the impact of smoking adjustment differed by cancer, sex and, to some extent, deprivation group.

\section{Laryngeal cancer}

Scenario 1 - Deprivation-specific life tables adjusted for smoking. In scenario 1, the impact on net survival estimates of adjusting the deprivation-specific life table for smoking was most pronounced for men with laryngeal cancer. One-year survival was 3.7\% higher and five-year survival was $7.2 \%$ higher when smoking-adjusted deprivation-specific life tables (highest level of adjustment, A3) were used instead of the unadjusted deprivation-specific life table. Among women with laryngeal cancer, 1-year survival was $0.9 \%$ higher and 5-year survival 1.7\% higher when smoking-adjusted life tables were used (Table 2). The impact of using smoking-adjusted life tables (S1) on net survival estimates was slightly more pronounced in the affluent groups, and, among men, the deprivation gap in survival widened by $1.6 \%$ at 5 years (Table 2).

Scenario 2 - National life tables adjusted for smoking. In scenario 2, the impact on net survival estimates of adjusting the national life table for smoking was similar to that under scenario 1 . In men, 1-year survival for laryngeal cancer was 3.5\% higher and 5year survival was $6.9 \%$ higher when national smoking-adjusted life tables (S2) were used instead of the unadjusted national life table. In women with laryngeal cancer, survival estimates were $0.9 \%$ higher at 1 year and $1.6 \%$ higher at 5 years (Table 3 ).

In women with laryngeal cancer, the impact of the national smoking-adjusted life tables (S2) on survival estimates was similar for all deprivation groups, so there was very little change to the deprivation gap in survival at 1 or 5 years (Table 3 ). In men with 
laryngeal cancer, the increase in survival when using the smokingadjusted life tables was again larger for the affluent groups, and so the deprivation gap in survival widened, by $1.5 \%$ at 1 year (from $-8.5 \%$ to $-10.0 \%$ ) and by $3.5 \%$ at 5 years (from $-11.2 \%$ to $-14.7 \%)$.

\section{Lung cancer}

Scenario 1 - Deprivation-specific life tables adjusted for smoking. Using smoking-adjusted life tables (both national and deprivationspecific) had a much smaller impact on net survival estimates for lung cancer than for laryngeal cancer. In men, 1-year survival was $1.4 \%$ higher and 5 -year survival was $1.5 \%$ higher when smokingadjusted deprivation-specific life tables were used (S1) instead of the unadjusted deprivation-specific life table. In women, there was very little change to the survival estimates when deprivationspecific life tables adjusted for smoking (S1) were used (Table 4). The impact on net survival estimates of the smoking-adjusted life tables was the same for all deprivation groups, so there was no change in the deprivation gap in survival for lung cancer for either sex.

Scenario 2 - National life tables adjusted for smoking. Net survival for lung cancer estimated with national smoking-adjusted life tables (under scenario 2) was very similar to survival estimated using smoking-adjusted deprivation-specific life tables (S1). Among men, both 1 - and 5-year net survival were $1.4 \%$ higher when national smoking-adjusted life tables (S1) were used instead of the unadjusted national life table (Table 5). In women with lung cancer, survival increased by less than $1 \%$ at both 1 and 5 years. This probably reflects the lower hazard rate ratios of all-cause mortality associated with smoking among women.

The impact of adjusting national life tables for smoking (S2) on the deprivation gap in survival for lung cancer was very small $(<1 \%)$ for both men and women. This is because the difference in survival between affluent and deprived patients with lung cancer is itself very small.

\section{DISCUSSION}

Smoking is the predominant cause of cancers of the larynx and lung, and is a significant cause of mortality in its own right. Estimates of net survival reflect the survival of the cancer patients adjusted for the background mortality in the general population. The background mortality in people who smoke, however, is considerably higher than in the general population, and the majority of laryngeal and lung cancer patients are expected to have been smokers.

The combination of the predominant aetiological factors having an unequal influence on overall mortality calls into question the use of standard life tables in the conventional approach to the estimation of net survival for cancers strongly related to smoking.

Table 2. One- and five-year net survival, and deprivation gap in survival for laryngeal cancer (England 2001-2005) using deprivation-specific unadjusted and deprivation-specific smoking-adjusted life tables, by sex

\begin{tabular}{|c|c|c|c|c|c|c|c|c|c|c|}
\hline \multirow[b]{3}{*}{$\begin{array}{l}\text { Deprivation } \\
\text { group }\end{array}$} & \multicolumn{5}{|c|}{ One-year net survival } & \multicolumn{5}{|c|}{ Five-year net survival } \\
\hline & \multicolumn{5}{|c|}{ Level of smoking adjustment ${ }^{b}$} & \multicolumn{5}{|c|}{ Level of smoking adjustment ${ }^{b}$} \\
\hline & Unadjusted $^{a}$ & $\begin{array}{l}\text { Lowest } \\
\text { (A1) }\end{array}$ & $\begin{array}{l}\text { Average } \\
\text { (A2) }\end{array}$ & $\begin{array}{l}\text { Highest } \\
\text { (A3) }\end{array}$ & $\begin{array}{c}\text { Maximum } \\
\text { difference }^{c}\end{array}$ & Unadjusted $^{\mathrm{a}}$ & $\begin{array}{l}\text { Lowest } \\
\text { (A1) }\end{array}$ & $\begin{array}{l}\text { Average } \\
\text { (A2) }\end{array}$ & $\begin{array}{l}\text { Highest } \\
\text { (A3) }\end{array}$ & $\begin{array}{l}\text { Maximum } \\
\text { difference }^{c}\end{array}$ \\
\hline \multicolumn{11}{|l|}{ Men } \\
\hline Overall & 84.3 & 85.7 & 86.8 & 87.9 & 3.7 & 75.4 & 78.2 & 80.3 & 82.6 & 7.2 \\
\hline Most affluent 1 & 88.9 & 90.3 & 91.6 & 92.9 & 4.0 & 79.8 & 82.5 & 85.0 & 87.8 & 8.0 \\
\hline 2 & 87.1 & 88.5 & 89.7 & 90.9 & 3.8 & 80.4 & 83.2 & 85.6 & 88.2 & 7.8 \\
\hline 3 & 84.4 & 85.8 & 87.0 & 88.1 & 3.8 & 75.7 & 78.5 & 80.8 & 83.2 & 7.5 \\
\hline 4 & 82.2 & 83.6 & 84.7 & 85.7 & 3.4 & 72.9 & 75.5 & 77.5 & 79.6 & 6.7 \\
\hline Most deprived 5 & 82.1 & 83.6 & 84.6 & 85.5 & 3.4 & 72.5 & 75.3 & 77.2 & 79.1 & 6.6 \\
\hline \multicolumn{11}{|l|}{ Women } \\
\hline Overall & 78.2 & 79.0 & 79.1 & 79.2 & 0.9 & 69.7 & 71.1 & 71.2 & 71.4 & 1.7 \\
\hline Most affluent 1 & 79.0 & 79.8 & 79.8 & 79.9 & 0.9 & 69.8 & 71.1 & 71.2 & 71.3 & 1.5 \\
\hline 2 & 82.1 & 82.8 & 82.9 & 83.0 & 0.9 & 71.7 & 72.8 & 73.0 & 73.1 & 1.5 \\
\hline 3 & 77.6 & 78.4 & 78.5 & 78.6 & 1.0 & 69.3 & 70.7 & 70.8 & 71.0 & 1.7 \\
\hline 4 & 79.2 & 79.9 & 80.0 & 80.1 & 0.9 & 71.4 & 72.8 & 72.9 & 73.0 & 1.7 \\
\hline \multirow[t]{4}{*}{ Most deprived 5} & 76.0 & 76.8 & 76.8 & 76.9 & 1.0 & 67.8 & 69.2 & 69.4 & 69.6 & 1.8 \\
\hline & \multicolumn{5}{|c|}{ Fitted deprivation gap in 1-year net survival } & \multicolumn{5}{|c|}{ Fitted deprivation gap in 5 -year net survival } \\
\hline & \multicolumn{5}{|c|}{ Level of smoking adjustment $^{\mathrm{b}}$} & \multicolumn{5}{|c|}{ Level of smoking adjustment ${ }^{b}$} \\
\hline & Unadjusted $^{a}$ & $\begin{array}{l}\text { Lowest } \\
\text { (A1) }\end{array}$ & $\begin{array}{l}\text { Average } \\
\text { (A2) }\end{array}$ & $\begin{array}{l}\text { Highest } \\
\text { (A3) }\end{array}$ & $\begin{array}{l}\text { Maximum } \\
\text { difference }^{d}\end{array}$ & Unadjusted $^{\mathrm{a}}$ & $\begin{array}{l}\text { Lowest } \\
\text { (A1) }\end{array}$ & $\begin{array}{l}\text { Average } \\
\text { (A2) }\end{array}$ & $\begin{array}{l}\text { Highest } \\
\text { (A3) }\end{array}$ & $\begin{array}{l}\text { Maximum } \\
\text { difference }^{\mathrm{d}}\end{array}$ \\
\hline Men & -7.1 & -7.1 & -7.4 & -7.8 & 0.6 & -8.8 & -8.8 & -9.4 & -10.4 & 1.6 \\
\hline Women & -4.6 & -4.6 & -4.5 & -4.5 & -0.1 & -2.7 & -2.5 & -2.4 & -2.4 & -0.3 \\
\hline \multicolumn{11}{|c|}{ 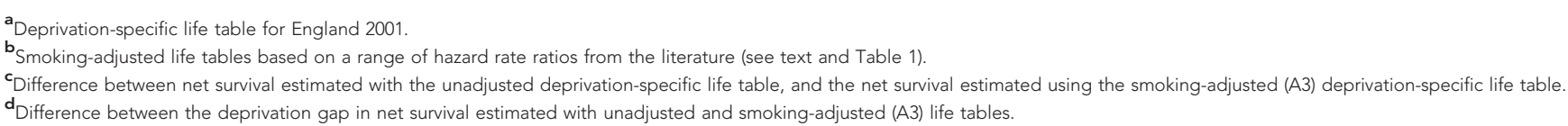 } \\
\hline
\end{tabular}




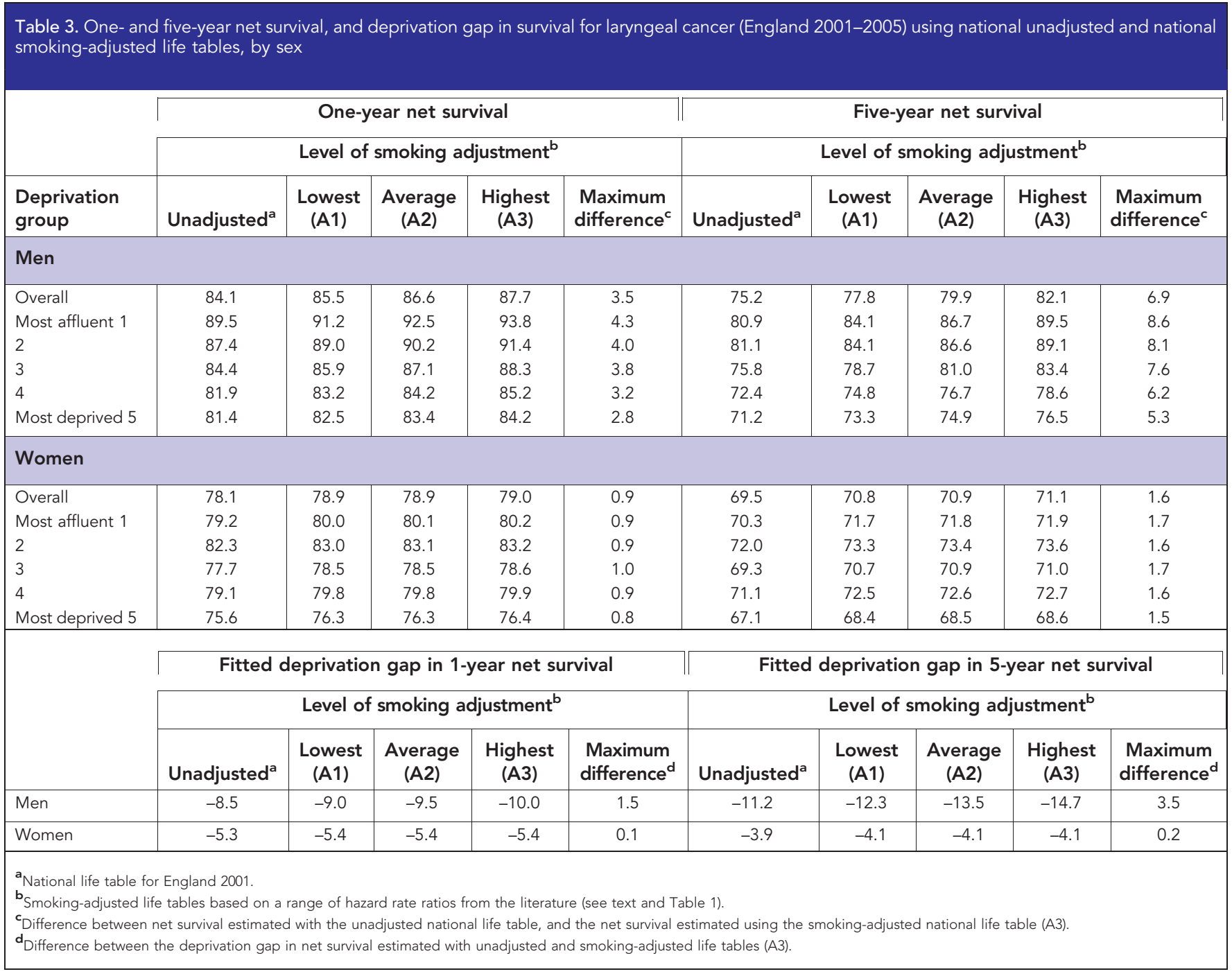

This is because the higher background mortality in smokers may not be adequately reflected in general population life tables.

We developed life tables adjusted for smoking, in order to examine the effect of the higher all-cause mortality among smokers on overall estimates of net survival for laryngeal and lung cancer, as well as on the deprivation gap in survival for those cancers.

The impact of adjusting life tables for smoking on net survival estimates for laryngeal and lung cancer (for all deprivation groups combined) was very similar whether using deprivation-specific (S1) or national (S2) life tables. The largest impact was among men diagnosed with laryngeal cancer, where the use of unadjusted life tables under-estimated net survival by up to $4 \%$ at 1 year since diagnosis, and up to $7 \%$ at 5 years since diagnosis. Among patients diagnosed with lung cancer, the impact of adjusting life tables for smoking on net survival estimates was negligible.

The estimation of the deprivation gap in survival (the fitted difference in survival between the most affluent and most deprived groups) was dependent on the assumptions made regarding the deprivation gradient in background mortality. As expected, using a national life table to estimate net survival resulted in the widest deprivation gap, because the known differences in background mortality by deprivation in the general population are not accounted for. However, if the assumption that all-cause mortality among smokers is identical, regardless of deprivation, is true, the use of a national life table in this instance may be appropriate. The deprivation gradient in all-cause mortality in the general population is undoubtedly due, in part, to differences in the prevalence of smoking between deprivation groups: estimates of the contribution of smoking to inequalities in mortality vary between 20 and $60 \%$ (Blakely and Wilson, 2005; van Rossum et al, 2005; Jha et al, 2006). It is, however, implausible that smoking is the only cause of this deprivation gradient, since this ignores other major social determinants of health inequalities, such as social conditions, neighbourhood deprivation and unemployment (Blakely and Wilson, 2006; Marmot, 2006). The use of deprivation-specific life tables produced a smaller deprivation gap in survival, although for laryngeal cancer the gap remained substantial. There is very little difference in survival between affluent and deprived lung cancer patients, because the prognosis is so poor, so the deprivation gap in survival is very small, regardless of the life tables used.

Compared to using an unadjusted national or deprivationspecific life table, adjusting life tables for smoking in order to estimate net survival tended to increase the deprivation gap for cancers where inequalities in survival exist. Substantial inequalities in survival exist for laryngeal cancer in men, but not in women, among whom no impact of the use of various life tables was observed.

These results raise several questions. First, it is possible that deprivation-specific life tables already take account of the differences in smoking prevalence, and hence the differences in all-cause mortality due to smoking, across deprivation groups. It 
Table 4. One- and five-year net survival, and deprivation gap in survival for lung cancer (England 2001-2005) using deprivation-specific unadjusted and deprivation-specific smoking-adjusted life tables, by sex

\begin{tabular}{|c|c|c|c|c|c|c|c|c|c|c|}
\hline \multirow[b]{3}{*}{$\begin{array}{l}\text { Deprivation } \\
\text { group }\end{array}$} & \multicolumn{5}{|c|}{ One-year net survival } & \multicolumn{5}{|c|}{ Five-year net survival } \\
\hline & \multicolumn{5}{|c|}{ Level of smoking adjustment $^{\mathrm{b}}$} & \multicolumn{5}{|c|}{ Level of smoking adjustment ${ }^{b}$} \\
\hline & Unadjusted $^{a}$ & $\begin{array}{l}\text { Lowest } \\
\text { (A1) }\end{array}$ & $\begin{array}{l}\text { Average } \\
\text { (A2) }\end{array}$ & $\begin{array}{l}\text { Highest } \\
\text { (A3) }\end{array}$ & $\begin{array}{l}\text { Maximum } \\
\text { difference }^{c}\end{array}$ & Unadjusted $^{\mathrm{a}}$ & $\begin{array}{l}\text { Lowest } \\
\text { (A1) }\end{array}$ & $\begin{array}{l}\text { Average } \\
\text { (A2) }\end{array}$ & $\begin{array}{l}\text { Highest } \\
\text { (A3) }\end{array}$ & $\begin{array}{l}\text { Maximum } \\
\text { difference }^{c}\end{array}$ \\
\hline \multicolumn{11}{|l|}{ Men } \\
\hline $\begin{array}{l}\text { Overall } \\
\text { Most affluent } 1 \\
2 \\
3 \\
4 \\
\text { Most deprived } 5\end{array}$ & $\begin{array}{l}26.3 \\
27.8 \\
26.0 \\
26.6 \\
26.0 \\
25.7\end{array}$ & $\begin{array}{l}26.8 \\
28.3 \\
26.6 \\
27.2 \\
26.5 \\
26.3\end{array}$ & $\begin{array}{l}27.3 \\
28.7 \\
27.0 \\
27.6 \\
27.0 \\
26.7\end{array}$ & $\begin{array}{l}27.7 \\
29.1 \\
27.4 \\
28.0 \\
27.4 \\
27.1\end{array}$ & $\begin{array}{l}1.4 \\
1.4 \\
1.4 \\
1.4 \\
1.4 \\
1.5\end{array}$ & $\begin{array}{l}13.6 \\
14.6 \\
13.4 \\
13.8 \\
13.1 \\
13.4\end{array}$ & $\begin{array}{l}14.1 \\
15.1 \\
13.9 \\
14.3 \\
13.7 \\
14.1\end{array}$ & $\begin{array}{l}14.6 \\
15.6 \\
14.4 \\
14.8 \\
14.1 \\
14.6\end{array}$ & $\begin{array}{l}15.1 \\
16.0 \\
14.9 \\
15.3 \\
14.5 \\
15.1\end{array}$ & $\begin{array}{l}1.5 \\
1.4 \\
1.5 \\
1.5 \\
1.4 \\
1.6\end{array}$ \\
\hline \multicolumn{11}{|l|}{ Women } \\
\hline $\begin{array}{l}\text { Overall } \\
\text { Most affluent } 1 \\
2 \\
3 \\
4 \\
\text { Most deprived } 5\end{array}$ & $\begin{array}{l}29.0 \\
31.9 \\
29.2 \\
29.8 \\
27.4 \\
28.2 \\
\end{array}$ & $\begin{array}{l}29.3 \\
32.2 \\
29.5 \\
30.2 \\
27.7 \\
28.6 \\
\end{array}$ & $\begin{array}{l}29.3 \\
32.2 \\
29.5 \\
30.2 \\
27.7 \\
28.6 \\
\end{array}$ & $\begin{array}{l}29.3 \\
32.2 \\
29.6 \\
30.2 \\
27.7 \\
28.7 \\
\end{array}$ & $\begin{array}{l}0.4 \\
0.4 \\
0.4 \\
0.4 \\
0.4 \\
0.4 \\
\end{array}$ & $\begin{array}{l}15.8 \\
17.4 \\
16.6 \\
16.1 \\
14.9 \\
15.3 \\
\end{array}$ & $\begin{array}{l}16.2 \\
17.7 \\
16.9 \\
16.4 \\
15.3 \\
15.6 \\
\end{array}$ & $\begin{array}{l}16.2 \\
17.7 \\
16.9 \\
16.4 \\
15.3 \\
15.7 \\
\end{array}$ & $\begin{array}{l}16.2 \\
17.8 \\
17.0 \\
16.5 \\
15.3 \\
15.7 \\
\end{array}$ & $\begin{array}{l}0.4 \\
0.4 \\
0.4 \\
0.4 \\
0.4 \\
0.4 \\
\end{array}$ \\
\hline & \multicolumn{5}{|c|}{ Fitted deprivation gap in 1-year net survival } & \multicolumn{5}{|c|}{ Fitted deprivation gap in 5-year net survival } \\
\hline & \multicolumn{5}{|c|}{ Level of smoking adjustment $^{b}$} & \multicolumn{5}{|c|}{ Level of smoking adjustment ${ }^{b}$} \\
\hline & Unadjusted $^{\mathrm{a}}$ & $\begin{array}{l}\text { Lowest } \\
\text { (A1) }\end{array}$ & $\begin{array}{c}\text { Average } \\
\text { (A2) }\end{array}$ & $\begin{array}{l}\text { Highest } \\
\text { (A3) }\end{array}$ & $\begin{array}{l}\text { Maximum } \\
\text { difference }^{d}\end{array}$ & Unadjusted $^{a}$ & $\begin{array}{l}\text { Lowest } \\
\text { (A1) }\end{array}$ & $\begin{array}{l}\text { Average } \\
\text { (A2) }\end{array}$ & $\begin{array}{l}\text { Highest } \\
\text { (A3) }\end{array}$ & $\begin{array}{c}\text { Maximum } \\
\text { difference }^{d}\end{array}$ \\
\hline $\begin{array}{l}\text { Men } \\
\text { Women }\end{array}$ & $\begin{array}{l}-1.6 \\
-3.3\end{array}$ & $\begin{array}{l}-1.5 \\
-3.3\end{array}$ & $\begin{array}{l}-1.5 \\
-3.3\end{array}$ & $\begin{array}{l}-1.5 \\
-3.3\end{array}$ & $\begin{array}{r}-0.1 \\
0.0\end{array}$ & $\begin{array}{l}-0.9 \\
-2.2\end{array}$ & $\begin{array}{l}-0.8 \\
-2.2\end{array}$ & $\begin{array}{l}-0.8 \\
-2.2\end{array}$ & $\begin{array}{l}-0.8 \\
-2.2\end{array}$ & $\begin{array}{r}-0.1 \\
0.0\end{array}$ \\
\hline 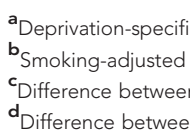 & $\begin{array}{l}\text { ble for Englar } \\
\text { les based on } \\
\text { urvival estimat } \\
\text { leprivation gar }\end{array}$ & $\begin{array}{l}01 . \\
\text { ge of ha } \\
\text { th the u } \\
\text { et surviv }\end{array}$ & $\begin{array}{l}\text { rate ratios } \\
\text { usted depr } \\
\text { timated wi }\end{array}$ & $\begin{array}{l}\text { the liter } \\
n-\text {-specific } \\
\text { adjusted }\end{array}$ & $\begin{array}{l}\text { see text and } \\
\text { able, and the }\end{array}$ & $\begin{array}{l}\text { 1). } \\
\text { survival estimate } \\
\text { life tables (A3). }\end{array}$ & ng the s & g-adjusted & rivation-s & ic life table (A3). \\
\hline
\end{tabular}

could therefore be argued that further adjustment to deprivationspecific life tables for the higher background mortality among smokers is not necessary. However, net survival for each of deprivation groups is clearly under-estimated when using unadjusted life tables.

Second, the method of constructing life tables for smokers presented here is not without its limitations. The lack of mortality and population data by smoking status meant that a life table could not be constructed directly from the raw data. Instead, crude adjustments were made to existing life tables. While the adjustments were made on the basis of published rate ratios, there is still margin for error. Studies that have sought to construct life tables for smokers directly from raw data are limited. One of the few countries that collect data on smoking at a population level is New Zealand, where it has been included in the census since 1996. The New Zealand census is linked to population mortality data, thus allowing life tables for smokers to be constructed directly from the raw data. A recent study suggests that the use of non-smokingspecific life tables could under-estimate the relative survival for bladder cancer in New Zealand by 10-25\% (Blakeley et al, 2012). A more modest effect was found for lung cancer. One study in Finland constructed life tables for smokers using a similar method to that presented here, but found that their use made little impact on estimates of relative survival for lung cancer compared to general population life tables (Hinchliffe et al, 2012). These findings replicate our own, and are not unexpected, because of the poor prognosis of lung cancer. Neither of these two studies directly examined the impact of using life tables for smokers on socioeconomic inequalities in cancer survival.

Our adjusted life tables consisted of the overall mortality associated with tobacco smoking, that is, including mortality from lung cancer. In theory, the mortality from lung cancer should have been removed during the building of the life tables adjusted for smoking. Indeed, cumulative lung cancer mortality among smokers increases with age and is not negligible in the elderly. However, we did not account for lung cancer mortality in our life tables because this component of age-specific mortality rates remains small. In addition, the range of estimates in the literature of age-specific lung cancer mortality rates attributable to tobacco smoking is quite wide: this would have increased the complexity of our scenarios without adding much insight.

We assumed that all laryngeal and lung cancer patients are or have been smokers, instead of $85 \%$ and $90 \%$, respectively (Anantharaman et al, 2011; Parkin, 2011), but further analyses with these proportions showed little or no impact on the survival estimates (results not shown).

Notwithstanding the limitations of the method, the findings presented here show that using life tables that are adjusted for the higher background mortality among smokers in the estimation of net survival only has a small impact on the deprivation gap in survival, even when inequalities are substantial (laryngeal cancer in men) (Rachet et al, 2008). Net survival is thus a robust and appropriate method for measuring inequalities in cancer-related survival, even for cancers that are strongly associated with 


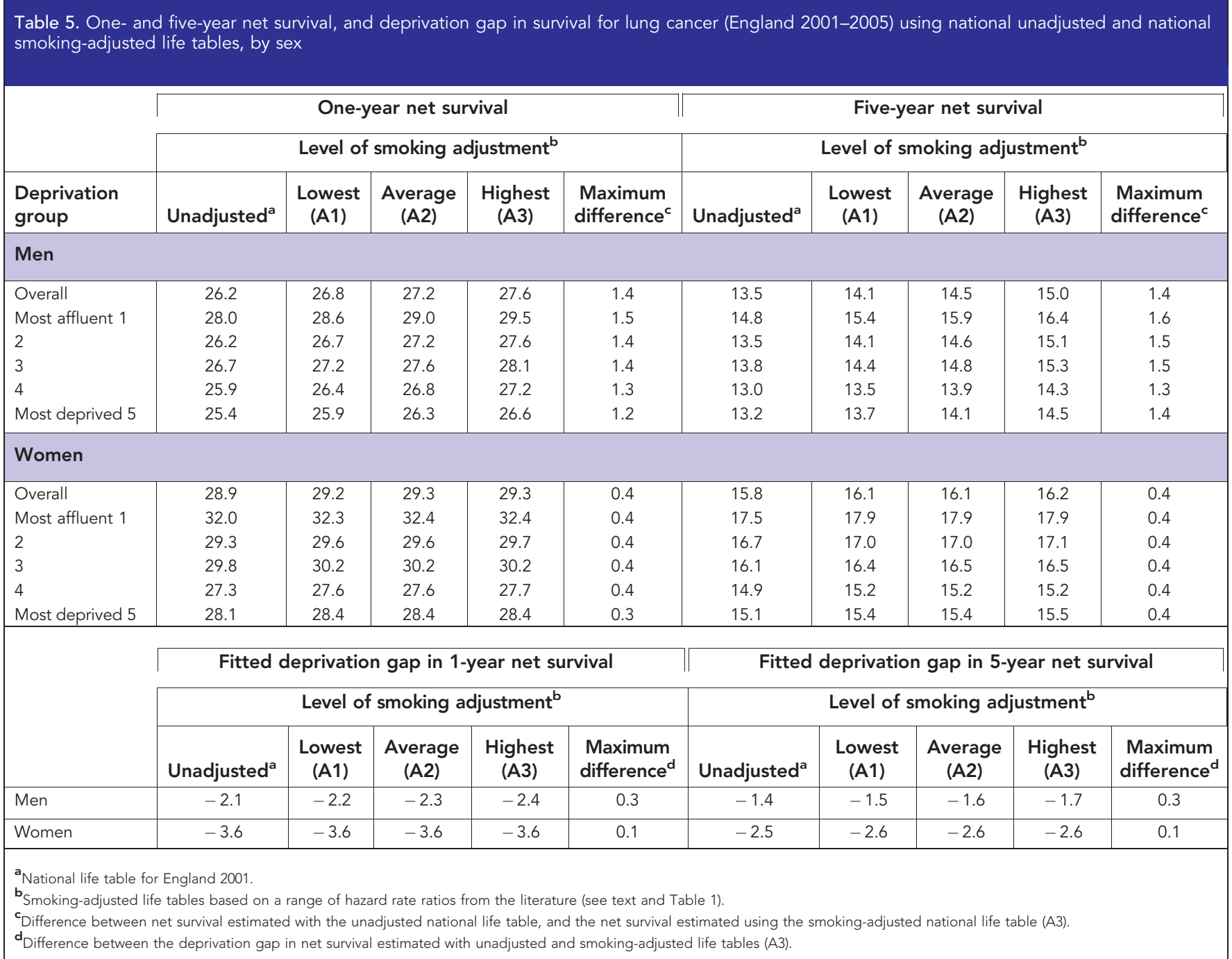

smoking. However, adjusting for the higher, smoking-related background mortality in the life tables did increase the estimates of net survival in all deprivation groups for good-prognosis cancers such as larynx. We can therefore conclude that life tables adjusted for smoking are not crucial for comparing net survival between populations, but may be more important for measuring the public health impact of differences and changes in survival, such as avoidable deaths (Abdel-Rahman et al, 2009; Ellis et al, 2012) or crude probabilities of death (Cronin and Feuer, 2000; Lambert et al, 2010).

\section{REFERENCES}

Abdel-Rahman M, Stockton D, Rachet B, Hakulinen T, Coleman MP (2009) What if cancer survival in Britain were the same as in Europe: how many deaths are avoidable? Br J Cancer 101(Suppl 2): S115-S124.

Anantharaman D, Marron M, Lagiou P, Samoli E, Ahrens W, Pohlabeln H, Slamova A, Schejbalova M, Merletti F, Richiardi L, Kjaerheim K, Castellsague X, Agudo A, Talamini R, Barzan L, Macfarlane TV, Tickle M, Simonato L, Canova C, Conway DI, McKinney PA, Thomson P, Znaor A, Healy CM, McCartan BE, Hashibe M, Brennan P, Macfarlane GJ (2011) Population attributable risk of tobacco and alcohol for upper aerodigestive tract cancers. Oral Oncol 47: 725-731.

Blakely T, Wilson N (2005) The contribution of smoking to inequalities in mortality by education varies over time and by sex: two national cohort studies, 1981-84 and 1996-99. Int J Epidemiol 34: 1054-1062.
Blakely T, Wilson N (2006) Letter in response to Jha et al (2006) (Lancet 368: 367-70). Lancet 368: 1418.

Blakely T, Soeberg M, Carter K, Costilla R, Atkinson J, Sarfati D (2012) Bias in relative survival methods when using incorrect life tables: lung and bladder cancer by smoking status and ethnicity in New Zealand. Int J Cancer 48: 270-278.

Cancer Research UK Cancer Survival Group (2009) Life tables for England and Wales by sex, calendar period, region and deprivation. London School of Hygiene \& Tropical Medicine. http://www.lshtm.ac.uk/eph/ncde/ cancersurvival/tools/index.html.

Carstensen JM, Pershagen G, Eklund G (1987) Mortality in relation to cigarette and pipe smoking: 16 years' observation of 25,000 Swedish men. J Epidemiol Community Health 41: 166-172.

Cronin KA, Feuer EJ (2000) Cumulative cause-specific mortality for cancer patients in the presence of other causes: a crude analogue of relative survival. Stat Med 19: 1729-1740.

Doll R, Peto R, Wheatley K, Gray R, Sutherland I (1994) Mortality in relation to smoking: 40 years' observations on male British doctors. Br Med J 309: 901-911.

Doll R, Peto R, Boreham J, Sutherland I (2004) Mortality in relation to smoking: 50 years' observations on male British doctors. $\mathrm{Br}$ Med J 328: 1519.

Ederer F, Axtell LM, Cutler SJ (1961) The relative survival rate: a statistical methodology. Natl Cancer Inst Monogr 6: 101-121.

Ellis L, Coleman MP, Rachet B (2012) How many deaths would be avoidable if socio-economic inequalities in cancer survival in England were eliminated? A national popyulation-based study. Eur J Cancer 48: 270-278. 
Ezzati M, Lopez AD (2003) Estimates of global mortality attributable to smoking in 2000. Lancet 362: 847-852.

Floderus B, Cederlöf R, Friberg L (1988) Smoking and mortality: a 21-year follow-up based on the Swedish Twin Registry. Int J Epidemiol 17: 332-340.

Gruer L, Hart CL, Gordon DS, Watt GC (2009) Effect of tobacco smoking on survival of men and women by social position: a 28 year cohort study. Br Med J 338: b480.

Hinchliffe SR, Rutherford MJ, Crowther MJ, Nelson CP, Lambert PC (2012) Should relative survival be used with lung cancer data? Br J Cancer 106: 1854-1859.

Illing EM, Kaiserman MJ (1995) Mortality attributable to tobacco use in Canada and its regions, 1991. Can J Public Health 86: 257-265.

Jacobs Jr DR, Adachi H, Mulder I, Kromhout D, Menotti A, Nissinen A, Blackburn H (1999) Cigarette smoking and mortality risk: twenty-fiveyear follow-up of the Seven Countries Study. Arch Intern Med 159: 733-740.

Jha P, Peto R, Zatonski W, Boreham J, Jarvis MJ, Lopez AD (2006) Social inequalities in male mortality, and in male mortality from smoking: indirect estimation from national death rates in England and Wales, Poland, and North America. Lancet 368: 367-370.

Kenfield SA, Stampfer MJ, Rosner BA, Colditz GA (2008) Smoking and smoking cessation in relation to mortality in women. J Am Med Assoc 299: 2037-2047.

LaCroix AZ, Lang J, Scherr P, Wallace RB, Cornoni-Huntley J, Berkman L, Curb JD, Evans D, Hennekens CH (1991) Smoking and mortality among older men and women in three communities. $N$ Engl J Med 324: 1619-1625.

Lambert PC, Dickman PW, Nelson CP, Royston P (2010) Estimating the crude probability of death due to cancer and other causes using relative survival models. Stat Med 29: 885-895.

Marmot M (2006) Smoking and inequalities. Lancet 368: 341-342.

Office for National Statistics (2010). General lifestyle survey 2008. Smoking and drinking among adults, 2008.

Nilsson S, Carstensen JM, Pershagen G (2001) Mortality among male and female smokers in Sweden: a 33 year follow up. J Epidemiol Community Health 55: 825-830.

Parkin DM (2011) Tobacco-attributable cancer burden in the UK in 2010. Br J Cancer 105: S6-S13.
Perme MP, Stare J, Esteve J (2012) On estimation in relative survival. Biometrics 68: 113-120.

Rachet B, Quinn MJ, Cooper N, Coleman MP (2008) Survival from cancer of the larynx in England and Wales up to 2001. Br J Cancer 99(Suppl 1): S35-S37.

Prescott E, Osler M, Andersen PK, Hein HO, Borch-Johnsen K, Lange P, Schnohr P, Vestbo J (1998) Mortality in women and men in relation to smoking. Int J Epidemiol 27: 27-32.

Qiao Q, Tervahauta M, Nissinen A, Tuomilehto J (2000) Mortality from all causes and from coronary heart disease related to smoking and changes in smoking during a 35-year follow-up of middle-aged Finnish men. Eur Heart J 21: 1621-1626.

Rodu B, Cole P (2004) The burden of mortality from smoking: comparing Sweden with other countries in the European Union. Eur J Epidemiol 19: 129-131.

Thun MJ, Day-Lally CA, Calle EE, Flanders WD, Heath Jr CW (1995) Excess mortality among cigarette smokers: changes in a 20 -year interval. Am J Public Health 85: 1223-1230.

Tverdal A, Thelle D, Stensvold I, Leren P, Bjartveit K (1993) Mortality in relation to smoking history: 13 years' follow-up of 68,000 Norwegian men and women 35-49 years. J Clin Epidemiol 46: 475-487.

van Rossum CTM, Shipley MJ, Van de Mheen H, Grobbee DE, Marmot MG (2005) Employment grade differences in cause specific mortality: a 25 year follow up of civil servants from the first Whitehall study. J Epidemiol Community Health 54: 178-184.

Vollset SE, Tverdal A, Gjessing HK (2006) Smoking and deaths between 40 and 70 years of age in women and men. Ann Intern Med 144: 381-389.

Woloshin S, Schwartz LM, Welch HG (2008) The risk of death by age, sex, and smoking status in the United States: putting health risks in context. J Natl Cancer Inst 100: 845-853.

Zorrilla-Torras B, García-Marín N, Galán-Labaca I, Gandarillas-Grande A (2005) Smoking attributable mortality in the community of Madrid: 1992-1998. Eur J Public Health 15: 43-50.

This work is published under the standard license to publish agreement. After 12 months the work will become freely available and the license terms will switch to a Creative Commons AttributionNonCommercial-Share Alike 3.0 Unported License. 